\title{
Waardenburg's syndrome and familial periodic paralysis
}

\author{
C. H. TAY \\ A.M., M.B., B.S., M.R.C.P.(Glas.)
}

Senior Medical Registrar and Clinical Teacher, Medical Unit II, Department of Clinical Medicine, University of Singapore, Outram Road General Hospital, Singapore, 3

\section{Summary}

Nine members in three generations of a Chinese family were found to have Waardenburg's syndrome comprising, mainly, lateral displacement of the inner canthi, broadening of the nasal root and hypertrichosis of the eyebrows. Other minor features were also found.

Two patients had in addition, hypokalemic periodic paralysis of the familial type, one had prominent frontal bossing and another, bilateral cleft lips and palate. These associated anomalies have not been previously documented and the presence of two autosomal dominant genetic defects in this family is of particular interest.

\section{Introduction}

In 1951, Waardenburg described a rare hereditary disease characterized by the following features: (1) lateral displacement of the inner canthi with dystopia canthrum, (2) broad nasal root, (3) confluent eyebrows with hypertrichosis of the medial ends, (4) heterochromia irides, (5) congenital deafness, (6) white forelock and (7) an autosomal dominant inheritance with variable penetrance.

Many complete and incomplete forms of this syndrome have been reported since the original description (Keizer, 1952; Wildervanck, 1957;
McKenzie, 1958; Fisch, 1959; Arnvig, 1958; $\vec{\omega}$ Partington, 1959; Di George, Olmsted \& Harley, 1960; Campbell, Campbell \& Swift, 1962; Chew, Chen \& Tan, 1968).

It is also known as a variant of the first $\operatorname{arch} v$ syndrome (McKenzie, 1958; Campbell et al., 1962) (r and later other minor characteristics of the syndrome ${ }^{\infty}$ were added: (1) abnormal depigmentation of the skin (Klein, 1950; Mende, 1926; Partington, 1959; Campbell et al, 1962), (2) pigmentary changes of the fundi (Waardenburg, 1951; Di George et al., 1960) and (3) abnormal facial appearance to maldevelopment of the maxilla and mandible (Fisch, 1959; Campbell et al., 1962).

In this paper, nine members in three generations $\frac{0}{9}-$ one Chinese family were found to have Waardec burg's syndrome. The interesting aspect of this family is the presence of hypokalemic periodic paralysis in two patients, frontal bossing in one and bilateral cleft lips and palate in another. None of $\frac{2}{2}$ these congenital anomalies has been previously $\overrightarrow{\vec{F}}$ documented. The association with familial periodic $\frac{3}{3}$ paralysis is of particular genetic interest, since the latter is also an autosomal dominant disease.

\section{Case reports}

Case 1 (Fig. 1; II, 1 arrowed)

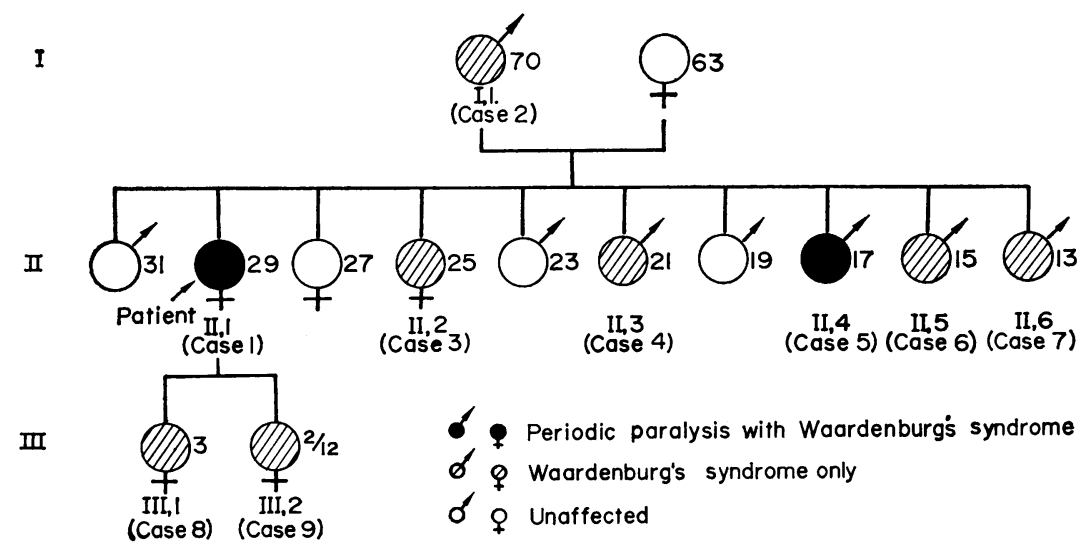

FIG.' 1 . The family tree. 
The propositus, a 27-year-old Chinese housewife, was admitted on 3 February 1970 when she suddenly became paralysed of all four limbs early that morning. Her speech, swallowing, breathing and sphincteric functions were not affected. There was no previous similar attack. She gave no history of vomiting, diarrhoea or excessive sweating and she denied taking any purgatives or drugs. Her general health had always been good.

Examination revealed a healthy adult with no evidence of dehydration, wasting or stunting. The thyroid was palpable but there were no signs of toxicity. The pulse was $86 / \mathrm{min}$, regular and of full volume, BP $110 / 80 \mathrm{mmHg}$. No abnormalities were detected in the heart, lungs or abdomen. All four limbs, including the neck, were flaccid, and the motor power, with the exception of that of the face, was markedly diminished. Sensory functions remained intact. All the deep tendon reflexes were reduced. The plantar responses were equivocal.

Incidental findings in this patient were: (1) increased intercanthal distance, $46 \mathrm{~mm}$ (normal Chinese adults-37-40 mm (Chew et al., 1968); there was also lateral displacement of lacrimal punctae. The interpupillary distance was normal (65 $\mathrm{mm}$ ) (normal adult range- $54-75 \mathrm{~mm}$ ), (2) broadening of nasal root, (3) hyperplasia of medial end of eyebrows, (4) heterochromia of the left iris and (5) a spray of white forelock (which she often concealed by combing) (Fig. 2). There was no deafness, confirmed by the audiogram, and no skin, fundal or skeletal changes. The following laboratory studies were within normal limits: complete blood count, complete urinalysis, ESR, blood urea nitrogen, basal metabolic rate, ${ }^{131}$ I-labelled triiodothyronine uptake, plasma PB ${ }^{131}$ I, thyroid antibodies (tanned red cell method), bilateral audiograms, X-rays of the skull, chest and abdomen, intravenous pyelograms, chromosome karyotypes and urinary electrolyte excretions.

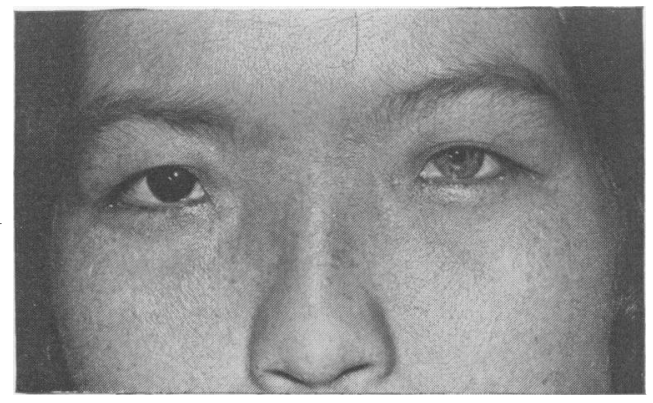

FIG. 2. Case 1 showing lateral displacement of inner canthi, broad nasal root, confluent eyebrows with hypertrichosis of the medial ends, and unilateral left heterochromia irides.
Serum potassium on admission was $1.8 \mathrm{mEq} / 1$, sodium $139 \mathrm{mEq} / 1$ and chloride $113 \mathrm{mEq} / \mathrm{l}$. ECG: prolonged $P R$ and $Q T$ intervals and prominent $U$ waves, consistent with hypokalemia.

The patient was treated with oral potassium chloride 3-6 $\mathrm{g}$ daily in divided doses and the motor power of her limbs rapidly returned to normal. Serum potassium on the third day was $3.6 \mathrm{mEq} / 1$, sodium $136 \mathrm{mEq} / 1$ and chloride $120 \mathrm{mEq} / 1$. ECG was now normal.

After discharge, she defaulted as she was staying a long distance away from the clinic. When she exhausted the supply of potassium tablets, she began to experience periodic weakness of her limbs. At first, these attacks were mild and readily aborted by drinking orange and other fruit juices, but later, the paralysis was severe and she was readmitted in March 1970. Serum potassium was found to be $2 \cdot 1$ $\mathrm{mEq} / \mathrm{l}$ and the serum sodium and chloride were normal. Again she improved with oral potassium supplements. Since then she has been on maintenance dose of potassium chloride $1 \mathrm{~g}$ thrice a day and remained symptom-free. The family tree of the patient was traced (Fig. 1) revealing eight more members in three generations with similar physical abnormalities. One brother (Case 5) also had periodic weakness of the limbs for about 6 months. The significant features of this family are summarized in Table 1.

\section{Case 2 (Fig. 1; I, 1)}

This 70-year-old male, father of the propositus, had been in excellent health. At a very young age, he migrated to Singapore from China and could not recall any disease present in his family. When seen, he had grey hair and was partially deaf because of his old age. The intercanthal distance was increased to $50 \mathrm{~mm}$ but the interpupillary measurement was normal $(66 \mathrm{~mm})$. There was broadening of the nasal root and confluent eyebrows with hypertrichosis of the medial ends. No ocular, fundal or skin changes were present and he gave no history of periodic weakness. His hearing had been good until the last 5 years.

\section{Case 3 (Fig. 1; II, 2)}

This 25-year-old Chinese girl, sister of the propositus, had no deafness or weakness of the limbs, and she had been enjoying good health. She was also found to have an increase in the intercanthal distance $(43 \mathrm{~mm})$ with lateral displacement of the lacrimal points, but with a normal interpupillary measurement. Her nasal root was somewhat prominent and there was marked hypertrichosis of the eyebrows (Fig. 3). There were no eye, skin, hair or auditory lesions. 
TABLE 1.

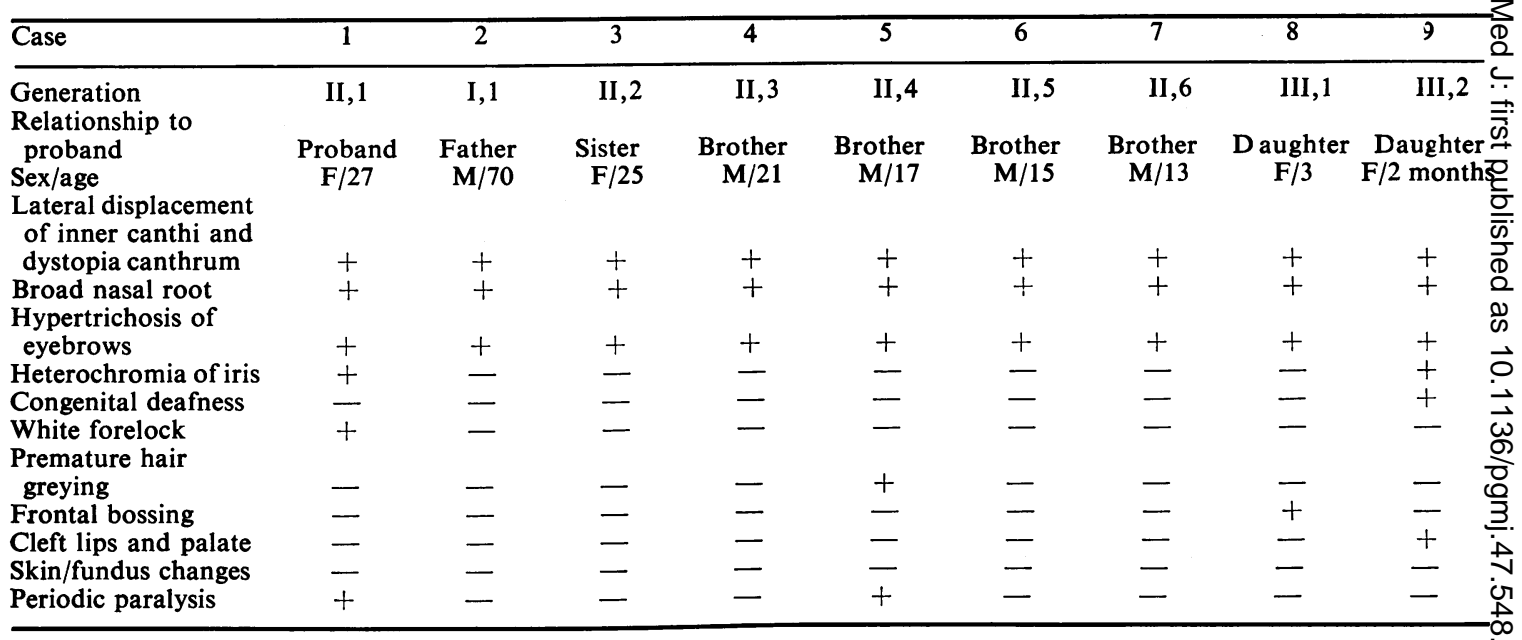

\section{Case 4 (Fig. 1: II, 3)}

This 21-year-old Chinese man, brother of the propositus, gave no history of periodic paralysis, deafness or skin diseases. His intercanthal distance was $41 \mathrm{~mm}$ and interpupillary measurement was normal $(65 \mathrm{~mm})$. There was some thickening of his eyebrows and his nasal root was broad (Fig. 4). No other abnormalities were found.

\section{Case 5 (Fig. 1; II, 4)}

This 17-year-old Chinese schoolboy, younger brother of the propositus, had had periodic weakness

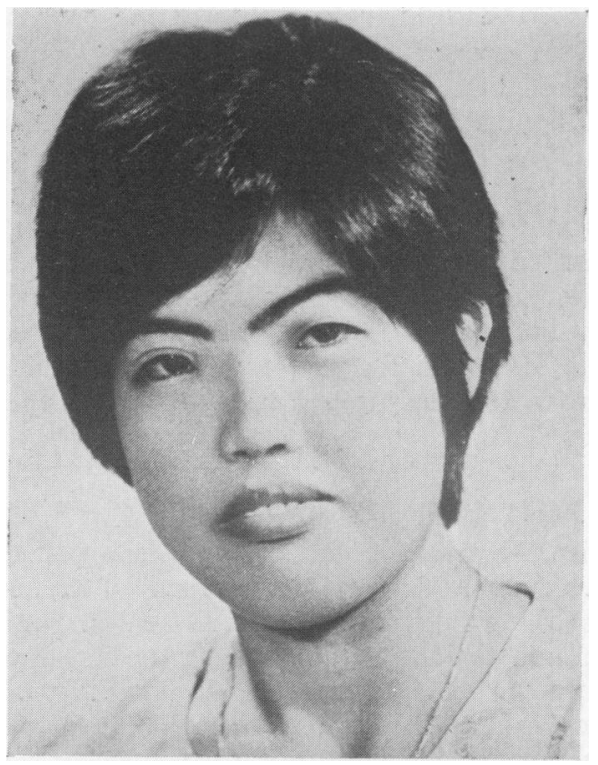

FIG. 3. Case 3. There is increased lateral displacement of the intercanthal distance, normal interpupillary measurement, widened nasal root and hypertrichosis of the eyebrows. and cramps of the legs for about 6 months. These w attacks were more frequent in the mornings and $\mathrm{O}_{0}^{+}$ after exercise. Relief of the weakness could some- times be obtained by drinking soft drinks like Coca- $\vec{c}$ Cola. He had no systemic disorders, but recently, some of his scalp hair had suddenly become prema- $\triangle$ turely grey. There were no skin, eye or auditory de-co fects. His intercanthal distance was increased 84 $\mathrm{mm}$ ) but the interpupillary distance was normal 56 $\mathrm{mm})$. There was also broadening of his nasal rogts and confluence of the brows with hypertrichosis of the medial portions (Fig. 5). Heterochromia, deaf-0 ness, skin and fundal changes were not present.

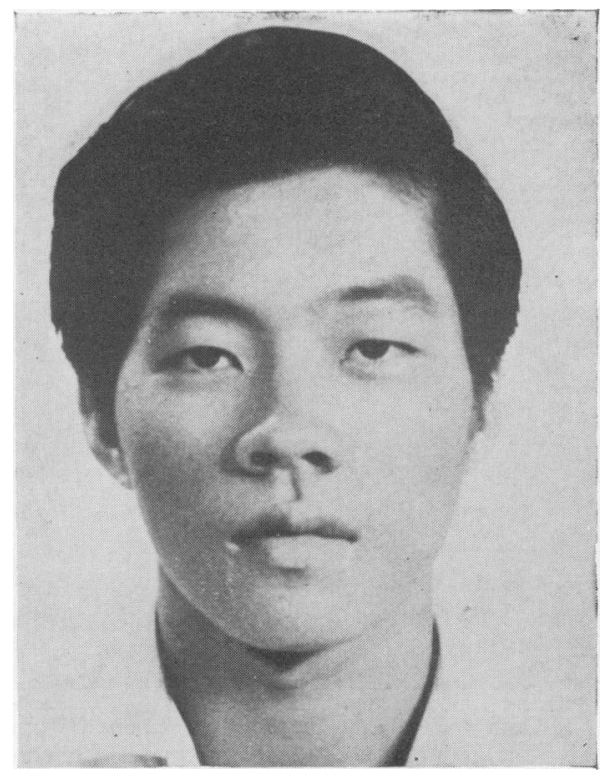

FIg. 4. Case 4 showing similar features as Case 3. 


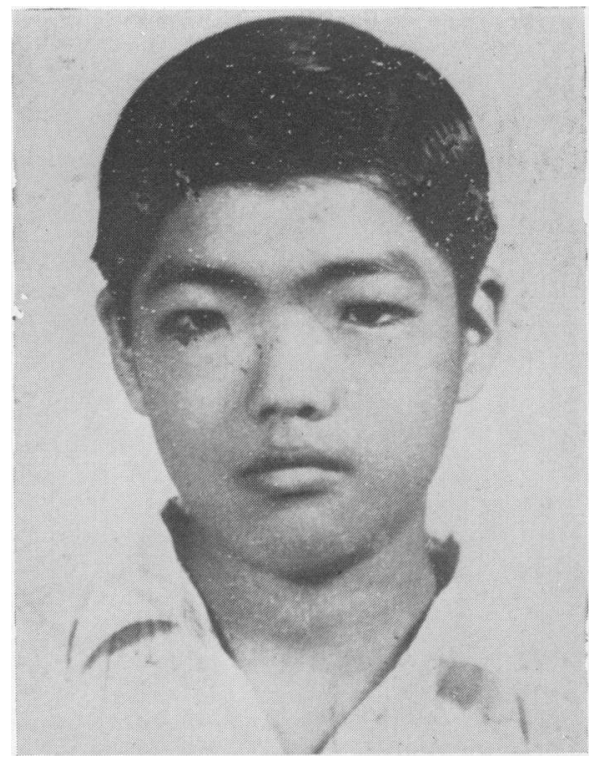

FIG. 5. Case 5 having similar features as Case 3, but in addition he, has early poliosis and hypokalemic periodic paralysis.

There was mild poliosis, but no white forelock. An audiogram was normal. The serum potassium during one of the attacks was low, $3 \cdot 1 \mathrm{mEq} / 1$ with normal values for the sodium and chloride. His weakness improved with oral potassium supplements. Most of the laboratory investigations were essentially normal.

\section{Case 6 (Fig. 1; II, 5)}

This 15-year-old Chinese schoolboy, another brother of the propositus, had no impairment of sight, hearing or power of the limbs. His intercanthal distance measured $39 \mathrm{~mm}$ and the interpupillary distance was $56 \mathrm{~mm}$. There was a noticeable broadening of the nasal root and the medial ends of the eyebrows were thickened. Heterochromia and other physical defects were absent (Fig. 6).

\section{Case 7 (Fig. 1; II, 6)}

The youngest brother of the propositus, a 13-yearold schoolboy, also had the same features as this brother-namely, the increased intercanthal distance $(34 \mathrm{~mm})$ with a normal interpupillary distance. The nasal root was widened and the medial portions of his eyebrows showed some hypertrichosis (Fig. 7). There were no eye, fundal, skin or auditory lesions and he never had muscular weakness. Both ears were found to be normal in function.

\section{Case 8 (Fig. 1; III, 1)}

This 3-year-old daughter of the propositus was born of a normal birth and her milestones were also

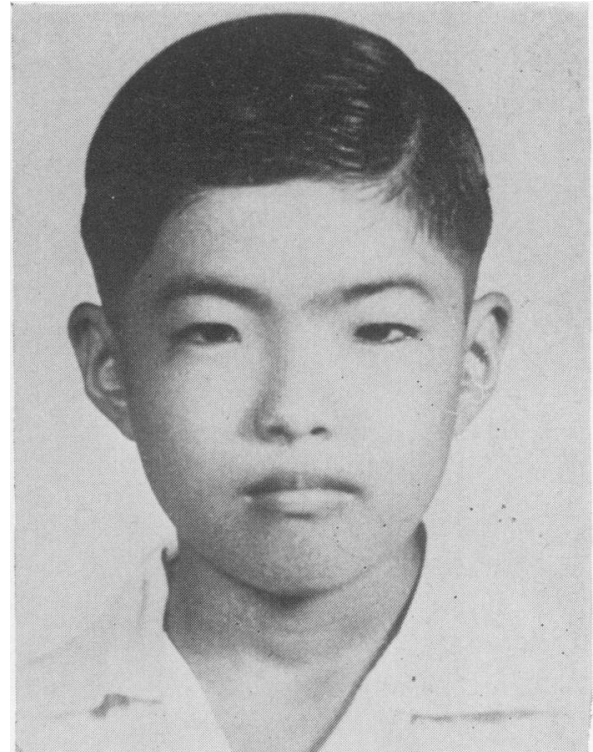

Fig. 6. Case 6. Same features as Case 3.

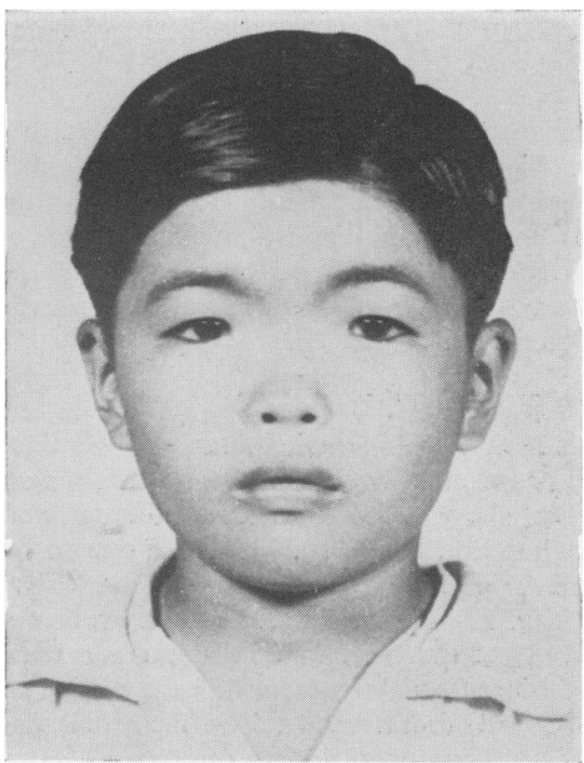

Fig. 7. Case 7. Same features as Case 3.

normal. She had no limb paralysis or other systemic illnesses. The intercanthal distance was $38 \mathrm{~mm}$ and the interpupillary distance $52 \mathrm{~mm}$ (normal ranges for the 3-10 age group are $22-30 \mathrm{~mm}$ for intercanthal distance, and 46-58 $\mathrm{mm}$ for the interpupillary distance: Waardenburg, 1951). The nasal root was widened and the brows are fairly thick. There was no evidence of deafness, heterochromia, hair or skin changes, but there was prominent frontal bossing 

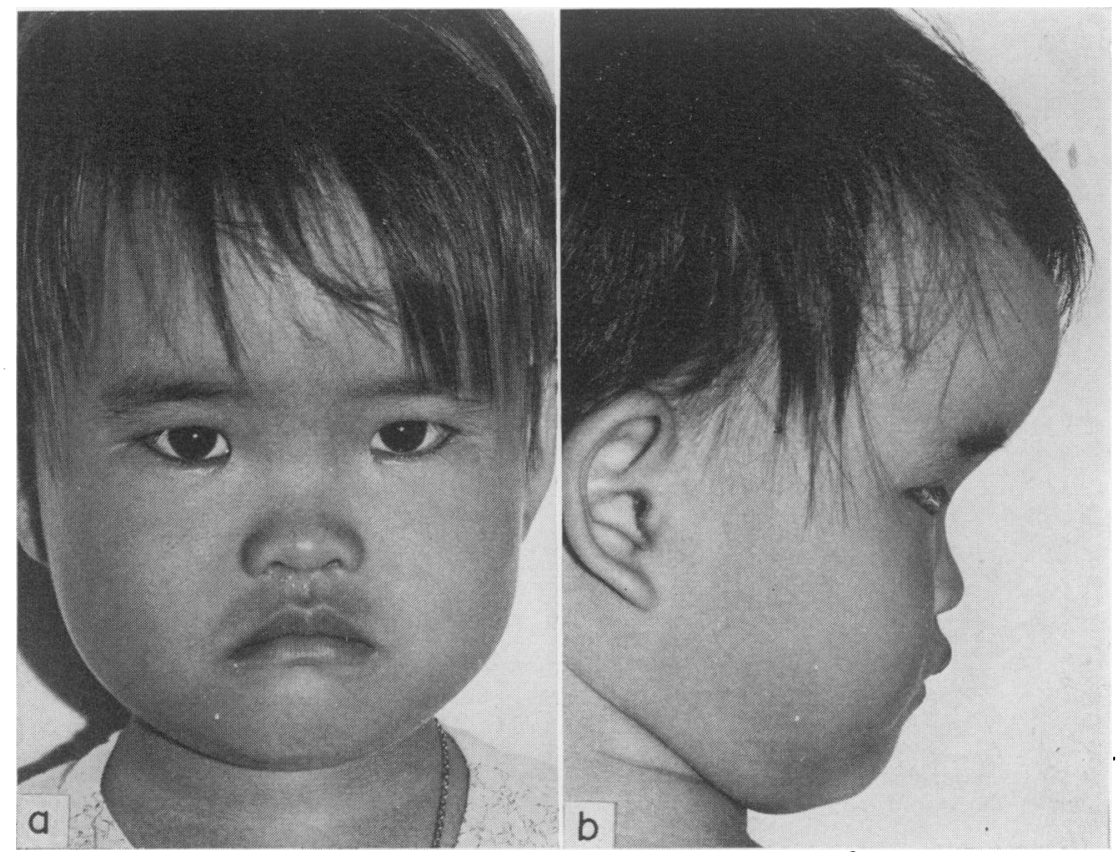

Fig. 8. (a) Case 8 showing similar appearance as Case 3; (b) side view of Case 8 showing marked frontal bossing.

measuring $59 \mathrm{~cm}$ in circumference, present since birth. (Fig. 8a and b.) The fundi were normal. There was no evidence of congenital syphilis or rickets and the serum calcium and phosphate levels were normal. Blood Kahn test was negative. Skull X-ray did not show any evidence of raised intracranial pressure or osseous defect.

\section{Case 9 (Fig. 1; III, 2)}

This 2-month-old female infant, younger daughter of the propositus, was born of a normal pregnancy. At birth, she was found to have bilateral cleft lips and palate and both eyes were blue due to heterochromia irides. The nasal root was markedly widened (Fig. 10). Hypertrichosis of the eyebrows was observed and the intercanthal distance was increased to $36.5 \mathrm{~mm}$ (normal range for this age group is 22-30 $\mathrm{mm}$, Waardenburg, 1951). The lachrimal punctae were found just anterior to the cornea and the distance between the two pupils was normal $(55 \mathrm{~mm})$. There were no hair or skin changes, and the ocular fundi were normal. The audiogram in this patient demonstrated bilateral perceptive deafness. No periodic paralysis occurred. Other systems were essentially normal and the laboratory tests were within normal limits. Chromosome karyotyping was also normal.

\section{Unaffected members of the family}

The mother of the propositus, her other three

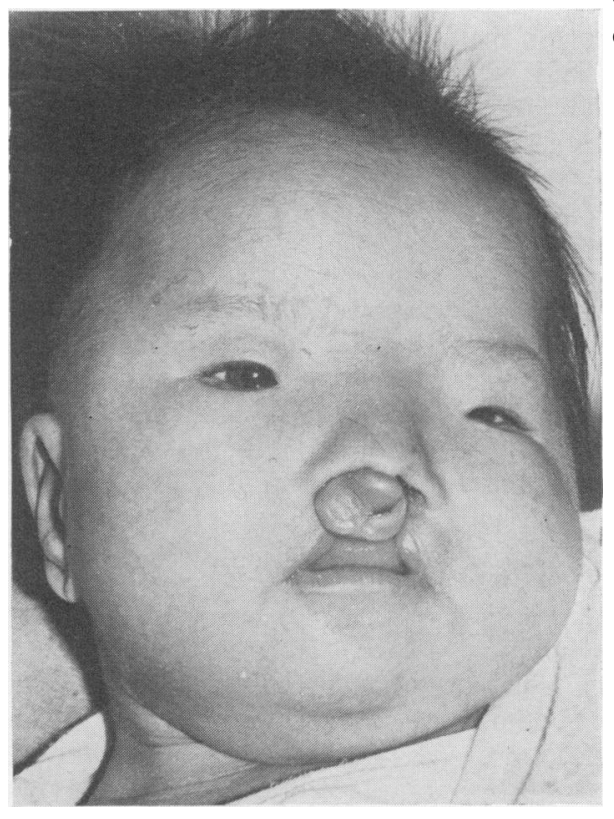

Fig. 9. Case 9 with prominent nasal root, widened inner canthi, hypertrichosis of brows, bilateral heterochromia $\frac{C}{D}$ irides and deafness, and bilateral cleft lips and palate.

brothers and one sister (Fig. 1) were examined an ${ }^{2}$ found to be normal without any stigmata of Waarden burg's syndrome. They had no symptoms oळ̂ 
paralysis, deafness and so forth. No physical abnormalities were detected. None of the mother's family suffered from Waardenburg's syndrome or periodic paralysis. Also unaffected were the propositus' husband and his parents.

\section{Discussion}

Nine members in this family had the major features of Waardenburg's syndrome-namely, the lateral displacement of the medial canthi and lacrimal punctae, the broadened nasal root, the confluent eyebrows and hypertrichosis of the medial portion, and various other characteristics shown in Table 1. All three generations were affected without any sexlinkage, demonstrating a simple autosomal dominant inheritance. This in fact, is the second Chinese family reported in Singapore as Chew et al. (1968) have reported another family with eight affected members having a fairly similar incidence of ocular and nasal changes. Heterochromia, deafness, hair and skin changes are rarely found. This is not surprising since the large series described by Waardenburg (1951) showed the following incidence of the various characteristics: (1) lateral displacement of the medial canthi and dystopia canthrum-99\%, (2) broad nasal root $-78 \%$, (3) confluent eyebrows with hypertrichosis of medial ends $-45 \%$, (4) heterochromia irides $-25 \%$, (5) congenital deafness $-20 \%$, and white forelock $-17 \%$. Indeed, only six out of 178 of his cases had all the abnormalities of the syndrome.

It was unfortunate that the family tree could not be further traced as the father left China at a tender age and had no recollection of any diseases present in his ancestors. Investigations also showed no direct connection between this family and Chew's family except that both were immigrants from Southern China.

The presence of the goitre in the propositus raised the possibility of thyrotoxic periodic paralysis when she was investigated for hypokalemic periodic weakness (Linder, 1955; Engel, 1961), but the diagnosis was not substantiated by the clinical signs or the thyroid function tests. The finding of another member, her younger brother (Case 5) with a similar condition was in favour of the periodic paralysis being of a familial type. The transmission of familial hypokalemic periodic paralysis may be autosomal dominant, autosomal recessive or even sporadic, but the majority of cases were transmitted as a simple autosomal dominant (Boeters 1939; Tyler \& Stephens, 1951).

Thus the association between the two autosomal dominant diseases in these two patients is noteworthy as the combined features have not been previously documented.

Although periodic paralysis has been described in some families with muscular dystrophies and some degenerative nervous diseases (Zierler, 1970), comprehensive reviews of familial periodic paralysis have not disclosed a close association with any known condition similar to that of Waardenburg's syndrome. (Holtzapple, 1905; Talbott, 1941; Gass, Cherkasky \& Savitsky, 1948; Hoffmann, 1952; Shy et al., 1961).

The combination of these diseases could imply a close genetic association of two autosomal conditions, most likely a direct transmission from the propositus' father. Thus, because of the difference in variable penetrance and expressivity of the two defects, six out of ten siblings had Waardenburg's syndrome while two had, in addition, familial periodic paralysis. There is another possibility of transmission. Periodic paralysis in this family might be a sporadic occurrence, or the condition could be an autosomal recessive inheritance with asymptomatic parents (Boeters, 1939). However, this form of transmission is rare. It is, therefore, unlikely that periodic paralysis is a feature of Waardenburg's syndrome and it must be regarded as a chance association in this family.

Two other new anomalies found in this family are congenital frontal bossing (Case 8) and bilateral cleft lips and palate (Case 9). These malformations, not due to any acquired causes, further support the hypothesis that Waardenburg's syndrome is a variant of the first arch syndrome (McKenzie, 1958; Fisch, 1959; Campbell et al., 1962). The latter condition comprises the following disorders: (1) TreacherCollins syndrome, (2) Pierre-Robins syndrome, (3) mandibular dysostosis, (4) congenital deafmutism, (5) cleft lips and palate, (6) hyperteleorism and (7) Hallerman-Streiff syndrome.

None of the above conditions has been reported with Waardenburg's syndrome though the association with malformation of the jaw had been documented (Fisch, 1959; Campbell et al., 1962).

It has been postulated that the physical defects of Waardenburg's syndrome are caused by the disturbance or failure of growth and development of the frontonasal and maxillary processes due to the defective blood supply by the stapedial artery to the first visceral arch during the third to fifth week of gestation (McKenzie, 1958; Fisch, 1959; Campbell et al., 1962). Thus it might be possible that the frontal bossing in Case 8 was caused by the disturbed growth or hypertrophy of the frontal processes, and the cleft lips and palate (Case 9) were due to the failure of development of the two lateral processes of the maxillary body.

\section{Acknowledgments}

I wish to thank Professor O. T. Khoo, head of Medical Unit II, for his kind permission to publish this paper and Miss Chong for the invaluable secretarial assistance. 


\section{References}

Arnvig, J. (1959) The syndrome of Waardenburg. Acta genetica et statistica medica, 9, 41.

BoEters, H. (1939) Erbleiden des Nerren systems beim Menschen. In: Handbuck der Erbbiologie des Menschen (Ed. by E. Just), p. 59. Springer Verlag, Berlin.

Campbell, B., Campbell, N.R. \& SwifT, S. (1962) Waardenburg's syndrome-a variation of the first arch syndrome. Archives of Dermatology, 86, 718.

Chew, K.L., Chen, A.J. \& TAN, K.H. (1968) A Chinese family with Waardenburg's syndrome. American Journal of Ophthalmology, 65, 174.

Di George, A.M., Olmsted, R.W. \& Harley, R.D. (1960) Waardenburg's syndrome-a syndrome of heterchromia of the irides, lateral displacement of the medial canthi and lacrimal puncta, congenital deafness and other characteristic associated defects. Journal of Pediatrics, 57, 649.

ENGEL, A.G. (1961) Thyroid function and periodic paralysis. American Journal of Medicine, 30, 327.

FisCH, L. (1959) Deafness as part of an hereditary syndrome. Journal of Laryngology and Otology, 73, 355.

Gass, H., Cherkasky, M. \& Savitsky, N. (1948) Potassium and periodic paralysis. Medicine, 27, 105.

HofmanN, W.W. (1952) The syndrome of periodic paralysis, Neurology, $2,1$.

Holtzapple, G.E. (1905) Periodic paralysis. Journal of the American Medical Association, 45, 1224.

KeIZER, D.P.R. (1952) Een Nieuwe Vorn Van Congenitale Enfelijke Doof heid (Syndroom Van Waardenburg). Nederlandsch tijdschrift voor geneeskunde, 96, 2541.

KLEIN, D. (1950) Albinisme, partiel (leucisme) avec surdimutite, blepharophimosis et dysplasie myo-osteo-articulasie. Helvetica paediatrica acta, 5, 38.
LINDER, M.A. (1955) Periodic paralysis with hyperthyroidism Annals of Internal Medicine, 43, 241.

McKenzie, J. (1958) The first arch syndrome. Archives Diseases of Childhood, 73, 477.

MENDE, I. (1926) Uber eine familie hereditar-degenerativer $\overrightarrow{\vec{F}}$ Taubstummer mit mongoloidiem Einschlag and teilwesem $\stackrel{?}{+}$ Leukismus der Hant und Haare. Archiv für Kinderheil-O kunde, 70, 214.

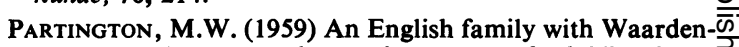
burg's syndrome. Archives of Diseases of Childhood, 34,, 154.

Shy, G.M., Wanko, T., Rowley, P.T. \& Engel, A.G. (1961) (1) Studies in familial periodic paralysis. Experimental $\vec{\circ}$ Neurology, 3, 53.

TALBOTt, J.H. (1941) Periodic paralysis-a clinical syndrome. $\vec{\omega}$ Medicine, 20, 85.

TYLER, F.H. \& STEPHENS, F.E. (1951) The clinical manifestaro tions and inheritance of a type of periodic paralysis with- 3 out hypopotassemia. Journal of Clinical Investigations, 30, 492.

WAARDENBURG, P.J. (1951) A new syndrome combining de- ن velopmental anomalies of the eyelids, eyebrows and nose $\varnothing$ root with pigmentary defects of the iris and head hair and with congenital deafness. American Journal of Human $\rightarrow$ Genetics, 3, 195.

WildervaNCK, L.S. (1957) Doof Stomme Kinderen met bet Syndroom van Waardenburg-Klein. Nederlandsch tijd-c schrift geneeskunde, 101, 1120.

ZIERLER, K.L. (1970) Diseases of the muscles. In: Biochemical ${ }^{\overparen{D}}$ Disorders in Human Disease (Ed. by R. H. S. Thompson \& $\overrightarrow{0}$ I. D. Wootton), 3rd edn, p. 489. J. \& A. Churchill, Londog. 